\title{
PROPOSTA PARA A INSERÇÃO DA VARIÁVEL MIGRAÇÃO EM SISTEMAS DE INDICADORES MUNICIPAIS
}

\author{
Duval Fernandes \\ Idamila Renata Pires Vasconcellos
}

\begin{abstract}
Resumo: A utilização de dados populacionais em sistemas de informações municipais não é recente. Tendo por base esses sistemas, a proposta deste trabalho é sugerir indicadores que possam ter em conta aspectos do movimento migratório nos municípios. As variáveis escolhidas são levantadas nos Censos de 1991 e 2000 , no quesito "migração de data fixa" relativa aos últimos cinco anos - o que permite identificar o município de origem e destino do migrante.
\end{abstract}

Palavras-chave: Migração. Fonte de dados. Sistema de informações.

Abstract: The use of population data in systems of municipal information is not recent. The proposal of this paper is to suggest, considering these systems, indicators that can have in account aspects of the migratory movement. The chosen variables are raised in the Censuses of 1991 and 2000, using data fix migration informations that allow to identify the origin and destination of the migrant.

Key words: Migration. Data base. Information system.

$\mathrm{A}$ utilização de dados populacionais em sistemas de informações municipais não é recente. $\mathrm{Na}$ maioria dos casos, o número de habitantes ou de subgrupos populacionais, por exemplo, definidos por sexo e idade, são as variáveis demográficas mais utilizadas. Associados a outros dados, servem de base para o cálculo de indicadores como "densidade demográfica", "taxa de alfabetização", etc.

Indicadores mais elaborados, como a "esperança de vida ao nascer" e "mortalidade infantil" (ou "mortalidade na infância"), são também encontrados, mas, apesar de utilizarem dados populacionais, requerem técnicas mais sofisticadas de cálculo e definição de hipóteses sobre o comportamento dos componentes da dinâmica demográfica. $\mathrm{Na}$ área da saúde, além desses dois indicadores, vários outros são calculados e apresentados em sistemas de in- formações que tratam de riscos e vulnerabilidade de grupos populacionais específicos.

Se, de um lado, algumas variáveis populacionais são amplamente empregadas, por outro, o componente migratório é relegado a um segundo plano. Quando se trata do desenho de cenários relacionados a questões sociais, há um tácito reconhecimento da importância da imigração. Algumas vezes, o movimento migratório é indicado, de forma equivocada, como sendo o responsável por problemas sociais, no local de destino, e pela estagnação econômica, na origem.

Todos os gestores públicos reconhecem a importância da análise de fatores de atração e expulsão da população, assim como a necessidade de avaliar, no âmbito do planejamento, os impactos de um aumento ou diminuição do número de habitantes em determinado município ou região. 
Apesar da sua importância, é raro encontrar dados sobre a migração nos sistemas de informações municipais. Essa lacuna pode ser explicada pela falta de dados confiáveis que permitam traçar o quadro das trocas municipais com a necessária periodicidade. Essas informações são disponíveis por meio dos censos - isto é, de dez em dez anos, ou em períodos mais curtos, por conta da contagem intercensitária - mas com dados limitados. Se o interesse está voltado para as Unidades da Federação ou Regiões Metropolitanas, é possível, por meio da Pesquisa Nacional por Amostra de Domicílios - PNAD, ter o quadro de dados em períodos de tempo mais curtos. Outras fontes, como os registros administrativos, também contêm dados sobre a migração, mas são restritos à população-alvo dos registros e, em alguns casos, pouco confiáveis.

A realização da II Conferência das Nações Unidas para os Assentamentos Humanos - Habitat-II, em Istambul, em 1996, representou um importante momento para a construção de indicadores relacionados ao desenvolvimento local. O Programa das Nações Unidas para os Assentamentos Humanos propôs aos países participantes a construção de 30 indicadores-chave e um conjunto de nove indicadores qualitativos, ${ }^{1}$ que relacionavam as diversas funções exercidas no meio urbano. No Brasil, quatro cidades foram selecionadas para a elaboração do quadro de indicadores, a saber: Brasília, Rio de Janeiro, Curitiba e Recife. Essa iniciativa tinha o propósito de incentivar as administrações locais ao uso de indicadores para o planejamento da ação pública, como também de permitir a comparação entre cidades no ambiente internacional.

Mesmo com algumas resistências, a proposta de incorporação de indicadores no planejamento urbano prosperou na área governamental. Seguindo algumas experiências bem sucedidas no âmbito municipal e estadual, a criação de um sistema de informações passou a ser considerada no Plano Plurianual de Investimentos - PPA (período 2000/2003) no rol dos programas afetos à Secretaria do Desenvolvimento Urbano da Presidência da República - Sedu/PR. Assim, o Programa de Gestão da Política de Desenvolvimento Urbano passa a incluir a criação de dois sistemas complementares de informações: o Sistema Nacional de Indicadores Urbanos - SNIU, cujo protótipo está disponível, com acesso via Internet, e o Sistema de Monitoramento e Avaliação de Programas e Projetos - SMAPP.

O SNIU, na versão atual, ${ }^{2}$ contempla 744 variáveis e indicadores divididos em quatro campos temáticos: ges- tão urbana, habitação, saneamento e transportes urbanos. Além desses campos, há informações sobre a dinâmica demográfica da população municipal que são disponibilizadas em um campo temático especial.

Tendo por base sistemas de informações municipais semelhantes ao SNIU, a proposta deste trabalho é sugerir um grupo de indicadores que levem em conta alguns aspectos do movimento migratório nos municípios. A proposta aqui esboçada não exaure as possibilidades do uso das informações censitárias para a definição de um quadro amplo sobre o processo migratório nos municípios brasileiros. O que vai pautar este trabalho é a necessidade de gerar informações para o grupo de municípios incorporados ao sistema e que, por razões técnicas, possam ser consideradas metodologicamente confiáveis e de fácil levantamento.

A primeira parte do texto trata da avaliação das possíveis fontes de informação para o conhecimento do processo migratório. Em seguida, são discutidas as principais técnicas para o uso das informações das fontes indicadas e é apresentado um quadro que sugere as variáveis que poderão ser levantadas, assim como os indicadores resultantes para inserção no sistema e a ilustração sobre o uso de alguns indicadores.

\section{UTILIZAÇÃO DE INFORMAÇÕES SOBRE MIGRAÇÃO}

Segundo Pressat (1976), define-se "migração" como o fenômeno demográfico caracterizado pelo deslocamento de um indivíduo do seu local de residência para um novo local. O Manual IV das Nações Unidas (1972, p. 2) define a migração como

un traslado de una zona definitoria de la migración a otra (o traslado a una distancia mínima especificada) se ha hecho durante un intervalo de migración determinado y que ha implicado un cambio de residencia.

Essas definições têm como característica comum a visão do deslocamento de um local de residência e referemse a movimentos de caráter permanente. No entanto, admitem também outros tipos de deslocamentos não migratórios. Por exemplo, aqueles que ocorrem entre o local de trabalho e a residência - chamado de "movimento pendular" - que são de capital importância para o planejamento urbano.

Tendo em conta a definição mais restrita de "deslocamentos permanentes", qualquer fonte que forneça infor- 
mações sobre o local de residência anterior e atual pode ser considerada para o estudo da migração - como registros administrativos e pesquisas censitárias, por exemplo. No caso do movimento pendular, devem ser consideradas as informações sobre os deslocamentos temporários, como "ida ao trabalho", e, assim, dependendo da disponibilidade de dados que envolvam o tempo despendido nos percursos e outras características, é possível realizar análises mais detalhadas.

\section{Fontes de Informação}

Censos Demográficos - Segundo Martine (1984), foi no Censo Demográfico de 1940 que, pela primeira vez, foram levantadas informações sobre a migração interna. Foram incluídas algumas indagações sobre a Unidade da Federação - UF de nascimento e a de residência de todos os recenseados. Dessa forma, definiu-se o migrante como "aquele que residia em uma UF diversa daquela de seu nascimento". Para os estrangeiros ou brasileiros naturalizados, foi pesquisado o ano em que fixou residência no Brasil.

No Censo Demográfico de 1950, foram feitas as mesmas questões sobre nascimento e residência. Segundo Martine (1984), comparando-se os resultados com aqueles obtidos no levantamento precedente, é possível estimar a migração líquida do período para cada UF. No entanto, em 1950 não foi perguntado para os estrangeiros e brasileiros naturalizados qual tinha sido o "ano de entrada no país".

Em 1960, além das perguntas sobre a UF de residência atual e a de nascimento, o conjunto de questões relativas à migração ampliou-se. As indagações visavam a saber se o indivíduo era natural do município de residência - o que permitia estimar, para cada município, a migração acumulada de não-naturais. As informações dos levantamentos anteriores recuperavam dois pontos no tempo - a UF de nascimento e a de residência atual. O Censo de 1960 indagou aos não-naturais dos municípios qual era a UF onde se localizava o município de residência anterior - o que permitiu recuperar um segmento a mais do processo migratório dos indivíduos. Outra inovação foi perguntar aos não-naturais sobre o tempo de moradia no atual município de residência. Apesar das inovações, os resultados não foram animadores em termos da utilização das informações, uma vez que, por diversos problemas, a publicação completa dos dados tardou décadas.

Em 1970, foram repetidos os mesmos quesitos utilizados no Censo de 1960. Além disso, foi acrescentada uma questão sobre a procedência, para saber se o domicílio anterior era localizado na região urbana ou rural. Em relação ao "tempo de residência sem interrupção", foram incluídas algumas perguntas sobre o município e a UF - o que permitiu observar a migração intra-estadual. Uma novidade introduzida em 1970 foi a pergunta relativa ao município em que o entrevistado trabalhava ou estudava.

É importante notar, segundo lembra Martine (1984), que a ampla utilização das informações sobre migração no Censo Demográfico de 1970 levou a propostas de importantes avanços no questionário do novo levantamento em 1980. Apesar das restrições financeiras, os quesitos relativos à migração foram dirigidos tanto aos naturais quanto aos não-naturais dos municípios, e outras duas modificações importantes foram introduzidas:

- pergunta específica em relação à migração intramunicipal;

- questão dirigida a todos os migrantes com menos de 10 anos de residência, sobre o nome do seu município de procedência. A questão relativa ao município de trabalho e estudo foi mantida.

Em termos de avanço para o estudo da migração, houve uma inovação muito importante no Censo de 1991: a incorporação do quesito que indaga o local de residência cinco anos antes ${ }^{3}$ (data fixa) da data de realização do censo. Essa questão, combinada com os quesitos relativos ao "tempo de residência" e "lugar de residência imediatamente anterior", gerou um quadro de informações sobre migração encontrado somente em censos de alguns poucos países. Vale notar que, apesar dos avanços, o quesito que indagava sobre o "local de estudo ou trabalho" foi suprimido.

A Contagem da População, de 1996, apesar do questionário simplificado, incluiu dois quesitos sobre migração. Um indagava se a pessoa residia no município em 1/9/1991, isto é, na data de referência daquele Censo, e outro perguntava em qual UF residia naquela data. É interessante notar que a questão está, em princípio, referindo-se a cinco anos antes da data de referência da Contagem, realizada em $1 / 8 / 1996$.

O Censo de 2000 utilizou 13 quesitos para o estudo da migração. Por conta de restrições financeiras, foram incluídas algumas modificações: dentre elas, a retirada da identificação do "município de residência imediatamente anterior", que ficou restrita à "UF" e "país estrangeiro". Foram mantidos os quesitos relativos à migração de data fixa, relacionada a cinco anos antes da data do censo. A 
questão sobre o "município onde o entrevistado trabalha ou estuda" foi reintroduzida.

Pesquisa Nacional por Amostra de Domicílios - Segundo Hakkert (1996), o primeiro levantamento da PNAD ocorreu no segundo trimestre de 1967. Inicialmente como pesquisa trimestral, a PNAD tinha por objetivo a coleta de informações socioeconômicas básicas para todo o país, à exceção das Regiões Norte e Centro-Oeste. No Distrito Federal, as informações eram levantadas uma vez por ano. Em 1972, a PNAD passou a ser anual; e, em 1973, foram incluídas na amostra a Região Norte (apenas as áreas urbanas) e a Região Centro-Oeste. Naquele ano, a pesquisa levantou informações em 90.629 domicílios. Após um período de interrupção, o questionário básico da pesquisa foi uniformizado em 1976, incluindo informações sobre os membros do domicílio, ocupação, renda e instrução. Com a exceção de 1979, também se investigou sistematicamente a fecundidade das mulheres de 15 anos e mais. Além do questionário básico, a PNAD contém um suplemento, cujo conteúdo varia anualmente, para permitir análise de assuntos específicos. Na PNAD de 2001, por exemplo, foram pesquisados 126.858 domicílios e foi agregado ao questionário básico o suplemento sobre o trabalho das crianças e adolescentes de 5 a 17 anos.

A partir de 1992 foram incluídos na PNAD quesitos sobre migração. Atualmente são encontradas 12 questões relacionadas à migração no questionário básico. Isso permite, entre outros pontos, identificar a UF de naturalidade do migrante, a UF de residência anterior e a UF de residência cinco anos antes da data do levantamento. Dessa forma, diferentemente dos resultados do Censo, não é possível identificar o município de origem do migrante e as analises ficam restritas às UFs. Segundo Cunha (2002), podem ser citadas três limitações ao uso da PNAD para estudos sobre a migração, a saber:

- o tamanho e o nível de representatividade da amostra não permite conhecer a realidade migratória dos municípios e das regiões dentro dos estados, com exceção de algumas regiões metropolitanas;

- a falta de coleta de informações da área rural da Região Norte compromete a comparação entre as UFs;

- a expansão da amostra é feita com base em projeções demográficas - o que pode levar a imprecisões das estimativas.

No entanto, é importante salientar que, apesar dessas limitações, a PNAD é um importante instrumento para o acompanhamento da evolução dos componentes da dinâmica populacional - aí incluída a migração, por conta da sua periodicidade anual. Torna-se, pois, uma fonte fundamental para o acompanhamento das tendências migratórias, apesar das limitações impostas pelo tamanho da amostra e pelo número reduzido dos quesitos.

Outras Fontes - Qualquer coleta de informação - seja uma pesquisa de campo pontual, sejam levantamentos contínuos - pode ser utilizada para obtenção de dados sobre migração. No entanto, deve-se ter em conta, nas análises dos resultados obtidos, os limites metodológicos de cada enquete e as possibilidades de comparação.

Dentre as pesquisas pontuais, podem ser destacadas aquelas que levantam informações sobre o mercado de trabalho, em especial a Pesquisa Mensal de Emprego PME do Instituto Brasileiro de Geografia e Estatística IBGE e a Pesquisa de Emprego e Desemprego - PED do Departamento Intersindical de Estatística e Estudos Socioeconômicos - Dieese e Fundação Seade. Nesses dois levantamentos, são incluídas questões que permitem avaliar a migração na área de abrangência das pesquisas. No entanto, por conta do tamanho da amostra e da área de cobertura, ${ }^{4}$ o uso dessas informações é muito restrito em termos espaciais.

Apesar do pouco uso da informação sobre migração coletada em registros administrativos, possivelmente no futuro essas fontes de dados contínuos poderão ter um amplo emprego para o acompanhamento do fluxo migratório, inter e intra-urbano. Nesse grupo, destacam-se os registros da Relação Anual de Informações Sociais - Rais, que contêm informações detalhadas sobre o mercado formal de trabalho. Como é um levantamento do universo, não haveria problema em utilizá-lo em termos de abrangência espacial. Por outro lado, as estimativas ficariam comprometidas por conta da cobertura e qualidade da informação, além de se tratar de registros sobre o mercado formal de trabalho - o que exclui grande parcela dos trabalhadores brasileiros.

Outra fonte utilizada para trabalhos relacionados à migração são os dados coletados pelo Ministério da Saúde através do Sistema de Mortalidade - SIM, Sistema de Nascidos Vivos - Sinasc e os registros da Autorização de Internação Hospitalar - AIH. A limitação no emprego desses dados fica por conta da qualidade da informação, da cobertura e da abrangência do universo captado. Alguns trabalhos, ainda embrionários, utilizando essas bases avaliam o impacto do fenômeno migratório sobre a 
demanda por serviços de saúde. O principal objetivo é conhecer a origem dos pacientes que buscam os serviços públicos de saúde e, assim, contribuir para equacionar, na medida do possível, o atendimento local.

\section{A Escolha da Fonte de Informações}

Várias fontes poderiam ser utilizadas para a construção de um quadro de indicadores sobre migração em um sistema de informações municipais. No entanto, é importante considerar, primeiramente, que esses dados deverão ter como base geográfica o município e, se possível, uma periodicidade que garanta a observação da evolução do processo migratório intra e inter municipal.

Em relação ao primeiro requisito, a fonte mais indicada, no momento, são os dados censitários, pois disponibilizam informações sobre entradas e saídas de migrantes para todos os municípios brasileiros. Dessa forma, é possível construir a "matriz cruzada municipal de entradas e saídas”, que permitirá identificar áreas de atração e expulsão. Ainda em relação ao aspecto geográfico, considerando-se a intensa modificação da base municipal, ${ }^{5}$ o mais indicado seria utilizar as informações mais recentes sobre a migração, isto é, os dados do Censo de 2000. Para determinar a evolução do processo migratório, sugere-se a incorporação das informações levantadas no Censo de 1991 ao quadro de variáveis. Nesse particular, deve-se ter em mente que, para aproximadamente $20 \%$ dos municípios pesquisados em 2000, não será possível fazer comparações com os resultados encontrados para 1991.

Caso as regiões metropolitanas venham a receber tratamento especial no sistema, o uso da PNAD poderá ser considerado. Então, seria possível fazer um acompanhamento do processo imigratório interestadual ano a ano. No entanto, devem ser consideradas as possíveis limitações metodológicas e de utilização dessas informações. ${ }^{6}$

\section{VARIÁVEIS E INDICADORES RELACIONADOS À MIGRAÇÃO PARA INCLUSÃO NO SISTEMA}

Desde o Censo de 1940, vários são os quesitos que tratam da migração interna nos diversos recenseamentos realizados no Brasil. As questões mais comuns são: se natural ou não do município; duração de residência; lugar da última residência; e lugar de residência em uma data no passado, usualmente cinco anos antes da data do censo. Além dos aspectos relacionados à migração interna, a migração internacional vem merecendo destaque por conta de sua importância no quadro nacional e em algumas regiões.

Segundo Rigotti (1999), o "lugar de nascimento" é a variável mais fácil de ser encontrada nos censos e permite classificar o informante como "migrante" ou "nãomigrante" - dependendo se nasceu, respectivamente, em município diferente daquele onde responde ao recenseamento ou se nasceu no local de coleta. A desvantagem do uso dessa informação é que o resultado obtido indica somente se as pessoas residem em município diverso daquele de nascimento, mas não trata nem do momento em que ocorreu a migração, no caso dos migrantes, nem se houve alguma etapa migratória cumprida pelos naturais - o que os transformaria em "imigrantes de retorno".

Com outras variáveis como "local de nascimento", o item "duração de residência" permite avançar nas análises e captar o "imigrante de retorno": uma pessoa que nasceu no município onde está sendo entrevistada, mas que residiu fora por algum tempo. Nesse caso, o tempo de residência deverá ser menor do que a idade declarada e os não-migrantes deverão ter a idade equivalente ao tempo de residência.

O lugar da última residência permite identificar como "migrante" aquele que em um momento qualquer, nos últimos 10 anos a contar da data do censo, residiu em um município diverso do de nascimento. Nesse caso, são considerados "migrantes" todos os que já moraram fora do local de nascimento, independentemente da data e do tempo de residência. A falta de referência temporal indica que, para melhor análise, é recomendável a combinação desse quesito com a informação sobre a "duração de residência".

Dentre os quesitos de um censo relacionado à migração, o mais simples, do ponto de vista analítico, é o que indaga sobre o "lugar de residência" em uma data fixa anterior à realização do censo - usualmente cinco anos antes. Nesse caso, o "migrante" é aquele que residia, cinco anos antes, em lugar diverso daquele em que está residindo. O "não-migrante" reside no mesmo local nas duas datas consideradas. Deve-se notar que, dentre os "nãomigrantes", estão incluídos aqueles que fizeram alguma migração no período considerado que antecede ao censo, mas que retornaram ao mesmo local de residência onde moravam cinco anos antes do censo.

A grande vantagem desse quesito é que ele permite calcular, para as pessoas com idade acima de cinco anos, 
as medidas convencionais de migração, como o saldo migratório que, segundo Magalhães (2003), deve ser considerado como "trocas líquidas migratórias" entre duas datas fixas.

Além desses quesitos, também há informações sobre a mobilidade pendular, ${ }^{8}$ a partir da pergunta sobre o município onde o entrevistado trabalha ou estuda. Dessa forma, pode-se estabelecer o fluxo de pessoas cujos deslocamentos atendem a necessidades de trabalho ou estudo.

Independente da informação censitária considerada, o ponto de capital importância é a necessidade de conceituar o "migrante", sempre considerando as restrições inerentes ao uso de cada tipo de variável (CARVALHO; RIGOTTI, 1998). Para a mensuração do volume de migrantes são empregadas técnicas indiretas ou diretas. Segundo Carvalho (1982)

os métodos indiretos são mais empregados para o cálculo do saldo migratório e a migração é estimada por resíduo, ou seja, é a diferença, no segundo censo, entre a população esperada e a efetivamente observada, supondo a ausência de erros nas declarações de idade, perfeita cobertura censitária e uso de funções de mortalidade e fecundidade adequadas.

Dessa forma, além da qualidade dos dados censitários, é preciso ter o conhecimento da mortalidade e fecundidade nas áreas em estudo.

No caso da mensuração direta, calcula-se o número de migrantes de um determinado período, sua origem e destino e, de forma diversa da empregada no método indireto, estima-se também o saldo migratório. Assim, dependendo da informação considerada, o conceito de "migrante" varia. Por exemplo, se o estudo utiliza a informação sobre "local de nascimento", o migrante será definido como aquele que reside, no momento do censo, em local diverso do de nascimento. Se a variável utilizada trata do "local de últi- ma residência", o migrante será aquele que, em algum momento dentro do período analisado, morou fora do local de nascimento, mesmo que a sua residência seja, no momento do censo, a cidade onde nasceu.

Tendo em conta as limitações impostas pela disponibilidade de informações no nível municipal e a facilidade do levantamento de dados para a aplicação da mensuração direta da migração, sugere-se a utilização desta última para a definição das variáveis a serem consideradas em um sistema que tenha por objetivo captar informações sobre a migração municipal.

\section{Variáveis Disponíveis nos Censos de 1991 e 2000 e Métodos}

Considerando o propósito deste trabalho - que é a apresentação de sugestões para a inclusão da variável "migração" em um sistema de informações municipais - algumas restrições de ordem prática e metodológica devem ser consideradas. Uma análise que envolvesse a comparação temporal entre o Censo de 1991 e o de 2000, esbarra na impossibilidade, para os fins propostos, de reconstruir a malha municipal de 1991 em 2000 e garantir a comparabilidade das informações para todos os municípios. Deve-se considerar, ainda, que nem todos os quesitos presentes no levantamento de 1991 foram mantidos em 2000. Assim, só é possível avaliar os dados comuns aos dois censos. Outro aspecto a ser considerado é que só as informações que contenham a referência municipal poderão ser utilizadas, pois o objetivo é construir a matriz de "trocas" municipais. Dessa forma, dados relativos apenas às UFs não serão levados em conta.

Nos Quadros 1 e 2 são apresentadas as questões que tratam da migração nos Censos Demográficos 1940 a 2000 e na Contagem de 1996. Considerando para os Censos de 1991 e 2000 as informações em comum, tem-se que, para a variá-

\section{QUADRO 1}

Quadro de Indicadores Propostos por Município

\begin{tabular}{ll}
\hline Indicador & Composição \\
\hline Taxa Líquida Migratória & Numerador: [número de imigrantes (menos imigrantes internacionais)] \\
- [número de emigrantes] & Denominador: população de 5 anos e mais \\
Taxa de Imigração & Numerador: [número de imigrantes (menos imigrantes internacionais)] \\
& Denominador: população de 5 anos e mais \\
Taxa de Emigração & Numerador: número de emigrantes \\
& Denominador: população de 5 anos e mais \\
\hline
\end{tabular}




\section{QUADRO 2}

Questões sobre Migração nos Censos Brasileiros e Contagem

Brasil - 1940-2000

\begin{tabular}{|c|c|}
\hline Ano & Questões \\
\hline$\overline{1940}$ & $\begin{array}{l}\text { - Se o recenseado nasceu no Brasil, declarar o estado; se no estrangeiro, o país } \\
\text { - Nacionalidade: brasileiro nato? Naturalizado brasileiro? Se estrangeiro, de que nação? } \\
\text { - Se é estrangeiro ou brasileiro naturalizado, em que ano fixou residência no Brasil? }\end{array}$ \\
\hline 1950 & $\begin{array}{l}\text { - Onde nasceu (nome da UF ou país estrangeiro)? } \\
\text {-É brasileiro nato, naturalizado brasileiro, ou estrangeiro? }\end{array}$ \\
\hline 1960 & $\begin{array}{l}\text { - Unidade da Federação ou país estrangeiro de nascimento } \\
\text { - Nacionalidade (brasileiro nato, naturalizado brasileiro, estrangeiro) } \\
\text { - Somente para as pessoas que não nasceram neste município: } \\
\text { - Número de anos em que reside neste município (se anteriormente residia na zona rural marque também) } \\
\text { - Unidade da Federação ou país estrangeiro em que residia antes de mudar-se para este município }\end{array}$ \\
\hline 1970 & $\begin{array}{l}\text { - Nacionalidade (brasileiro nato, brasileiro naturalizado, estrangeiro) } \\
\text { - Unidade da Federação ou país estrangeiro de nascimento } \\
\text { - Nasceu neste município? (sim/não) } \\
\text { - Somente para as pessoas que responderam não no quesito } 10 \text { (anterior) } \\
\text { - Há quanto tempo mora nesta Unidade da Federação? } \\
\text { - Há quanto tempo mora neste município? } \\
\text { - Em que Unidade da Federação ou país estrangeiro residia antes de mudar para este município? } \\
\text { - Situação da residência no município onde morava anteriormente (cidade ou vila, povoado ou zona rural) } \\
\text { - Município onde trabalha ou estuda }\end{array}$ \\
\hline 1980 & $\begin{array}{l}\text { - Nacionalidade (brasileiro nato, brasileiro naturalizado, estrangeiro) } \\
\text { - Unidade da Federação ou país estrangeiro de residência } \\
\text { - Nasceu neste município? (sim/não) } \\
\text { - Neste município morou: só na zona rural, só na zona urbana, nas zonas urbana e rural } \\
\text { - No município onde residia anteriormente morava: na zona urbana, na zona rural, nasceu - quem sempre morou no município) } \\
\text { - Há quantos anos mora nesta Unidade da Federação? } \\
\text { - Há quantos anos mora neste município? } \\
\text { - Se no quesito } 17 \text { (anterior) respondeu menos de } 10 \text { anos, indique o nome do município e a sigla da Unidade da Federação ou } \\
\text { país estrangeiro em que morava antes } \\
\text { - Município em que trabalha ou estuda }\end{array}$ \\
\hline 1991 & $\begin{array}{l}\text { - Neste município morou: só na zona urbana, só na zona rural, nas zonas urbana e rural } \\
\text { - Se no quesito } 12 \text { (anterior) assinalou o retângulo } 3 \text { (nas zonas urbana e rural), indique a quantos anos se deu a última mudança. } \\
\text { - Nasceu neste município? (sim e sempre morou neste, sim mas já morou em outro, não nasceu) } \\
\text { - Se naturalizado brasileiro ou estrangeiro, indique o ano em que fixou residência no país } \\
\text { - Unidade da Federação ou país estrangeiro de nascimento } \\
\text { - Há quantos anos mora sem interrupção: nesta Unidade da Federação, neste município } \\
\text { - Para as pessoas com menos de } 10 \text { anos de moradia no município: } \\
\text { - Indique a sigla da UF e o nome do município ou país estrangeiro em que morava antes de mudar para este município } \\
\text { - Na localidade indicada no quesito } 19 \text { (anterior), residia: (na zona urbana, na zona rural) } \\
\text { - Os quesitos seguintes só serão preenchidos para as pessoas de } 5 \text { anos ou mais nascidos antes de 01/09/1986. } \\
\text { - Indique a sigla da UF e o nome do município ou país estrangeiro em que residia em 01/09/1986. } \\
\text { - Na localidade indicada no quesito } 21 \text { (anterior), antes de mudar, residia: (na zona urbana, na zona rural) }\end{array}$ \\
\hline 1996 & $\begin{array}{l}\text { - Em 01/09/91 residia neste município? (nasceu após a data, sim/não) } \\
\text { - Em que Unidade da Federação residia? }\end{array}$ \\
\hline 2000 & $\begin{array}{l}\text { - Mora neste município desde que nasceu? (sim/não) } \\
\text { - Há quanto tempo mora sem interrupção neste município? } \\
\text { - Nasceu neste município? (sim/não) } \\
\text { - Nasceu nesta Unidade da Federação? (sim/não) } \\
\text { - Qual é a sua nacionalidade? (brasileiro nato, naturalizado brasileiro, estrangeiro) } \\
\text { - Em que ano fixou residência no Brasil? } \\
\text { - Qual é a Unidade da Federação ou país estrangeiro de nascimento? } \\
\text { - Há quanto tempo mora sem interrupção nesta Unidade da Federação? } \\
\text { - Qual é a Unidade da Federação ou país estrangeiro de residência anterior? } \\
\text { - Onde residia no dia } 31 \text { de julho de 1995? } \\
\text { - Neste município na zona urbana } \\
\text { - Neste município na zona rural } \\
\text { - Em outro município, na zona urbana } \\
\text { - Em outro município, na zona rural } \\
\text { - Em outro país } \\
\text { - Não era nascido. } \\
\text { - Em que município residia em } 31 \text { de julho de 1995? } \\
\text { - Em que Unidade da Federação ou país estrangeiro residia em } 31 \text { de julho de 1995? } \\
\text { - Em que município e Unidade da Federação ou país estrangeiro trabalha ou estuda? }\end{array}$ \\
\hline
\end{tabular}

Fonte: IBGE. 
vel "local de nascimento", podem ser identificados, para os não-naturais, o país estrangeiro ou a UF de nascimento, assim como o tempo de residência no município. Para os estrangeiros e brasileiros naturalizados, é possível saber o tempo de residência no Brasil. Para todos os moradores, foi perguntado o tempo de residência na UF.

Em relação ao quesito "data fixa", nos últimos cinco anos, é possível identificar a migração rural-urbana intramunicipal. Para aqueles que residiam em cidades diferentes nos dois momentos - uma data fixa (1/9/86 para o Censo de 1991 e 31/7/95 para o Censo de 2000) e na data do censo - é possível identificar a situação do domicílio no município de origem, o nome do município, a UF; e, para os que residiam fora do Brasil, o país. No Censo de 2000, o último quesito do bloco trata da mobilidade pendular e é possível identificar o município, UF ou país estrangeiro onde o entrevistado trabalha ou estuda.

Pelo exposto, observa-se que a única informação disponível nos Censos de 1991 e 2000, que permite a identificação do município de origem dos imigrantes, é aquela relativa à "data fixa", que será considerada em nossa análise, em conjunto com os dados relativos à mobilidade pendular levantados no Censo de 2000.

\section{A Variável Migração no Sistema de Informações Municipais}

Para a definição das variáveis relativas à migração em um sistema de informações municipais, dois aspectos deverão ser considerados: um, tratando da migração no senso estrito, isto é, "modificação no local de residência"; e outro, sobre a mobilidade pendular. No primeiro caso, o migrante será, para 1991 e 2000, a pessoa que em 1o de setembro de 1986 e em 31 de julho de 1995, respectivamente, residia em um município diferente daquele em que morava na data do censo. Em relação à mobilidade pendular, em 2000, os "moventes" serão considerados aqueles que trabalham ou estudam em município diferente do de residência.

Para a migração definida por meio de data fixa, as variáveis sugeridas são listadas nos Quadros 3 e $4:^{9}$

- migração rural/urbana no município de residência. Imigrante rural/urbano - pessoa $^{10}$ que: a) para 1991, em $1^{\text {o }}$ de setembro de 1986 residia na região rural do município e que em $1^{\circ}$ de setembro de 1991 estava na região urbana do mesmo município; b) para 2000, em 31 de julho de 1995 residia na região rural do município e que em $1^{\circ}$ de agosto de 2000 estava na região urbana do mesmo município;

QUADRO 3

Quadro de Variáveis para o Município A

Brasil - 1991

\begin{tabular}{|c|c|c|}
\hline \multirow{2}{*}{ Variável } & \multicolumn{2}{|c|}{ Situação de Residência } \\
\hline & Em 1으 de setembro de 1986 & Em 1ㅇde setembro de 1991 \\
\hline \multicolumn{3}{|l|}{ Migração Intramunicipal } \\
\hline Imigrante rural/urbano & Residia na área rural do município $A$ & Residia na área urbana do município $\mathrm{A}$ \\
\hline Imigrante urbano/rural & Residia na área urbana do município A & Residia na área rural do município A \\
\hline \multicolumn{3}{|l|}{ Migração Intermunicipal (1) } \\
\hline Imigrante & Residia em outro município excluindo país estrangeiro & Residia no município A \\
\hline Emigrante & Residia no município A & Residia em outro município \\
\hline Imigrante rural/urbano & Residia na zona rural de outro município & Residia na zona urbana do município $A$ \\
\hline Imigrante urbano/urbano & Residia na zona urbana de outro município & Residia na zona urbana do município $A$ \\
\hline Imigrante rural/rural & Residia na zona rural de outro município & Residia na zona rural do município $A$ \\
\hline Emigrante rural/urbano & Residia na zona rural do município $A$ & Residia na zona urbana de outro município \\
\hline Emigrante urbano/urbano & Residia na zona urbana do município $A$ & Residia na zona urbana de outro município \\
\hline Emigrante rural/rural & Residia na zona rural do município $A$ & Residia na zona rural de outro município \\
\hline \multicolumn{3}{|l|}{ Migração Internacional } \\
\hline Imigrante internacional & Residia no exterior & Residia no município A \\
\hline \multicolumn{3}{|l|}{ Migração de Retorno (2) } \\
\hline Imigrante de retorno & Residia em outro município & Residia no município A \\
\hline
\end{tabular}

Fonte: IBGE. Censo Demográfico.

(1) Esta variável pode ser construída considerando, em separado, a migração interestadual e intra-estadual.

(2) Para os naturais do município $A$. 
QUADRO 4

Quadro de Variáveis para o Município A

Brasil - 2000

\begin{tabular}{|c|c|c|}
\hline \multirow[t]{2}{*}{ Variável } & \multicolumn{2}{|c|}{ Situação de Residência } \\
\hline & Em 31 de julho de 1995 & Em $1^{\circ}$ de agosto de 2000 \\
\hline \multicolumn{3}{|l|}{ Migração Intramunicipal } \\
\hline Imigrante rural/urbano & Residia na área rural do município $A$ & Residia na área urbana do município $A$ \\
\hline Imigrante urbano/rural & Residia na área urbana do município $A$ & Residia na área rural do município $A$ \\
\hline \multicolumn{3}{|l|}{ Migração Intermunicipal (1) } \\
\hline Imigrante & Residia em outro município excluindo país estrangeiro & Residia no município A \\
\hline Emigrante & Residia no município A & Residia em outro município \\
\hline Imigrante rural/urbano & Residia na zona rural de outro município & Residia na zona urbana do município $A$ \\
\hline Imigrante urbano/urbano & Residia na zona urbana de outro município & Residia na zona urbana do município $A$ \\
\hline Imigrante rural/rural & Residia na zona rural de outro município & Residia na zona rural do município $\mathrm{A}$ \\
\hline Emigrante rural/urbano & Residia na zona rural do município A & Residia na zona urbana de outro município \\
\hline Emigrante urbano/urbano & Residia na zona urbana do município $A$ & Residia na zona urbana de outro município \\
\hline Emigrante rural/rural & Residia na zona rural do município $\mathrm{A}$ & Residia na zona rural de outro município \\
\hline \multicolumn{3}{|l|}{ Migração Internacional } \\
\hline Imigrante Internacional & Residia no exterior & Residia no município A \\
\hline \multicolumn{3}{|l|}{ Migração de Retorno (2) } \\
\hline Imigrante de retorno & Residia em outro município & Residia no município A \\
\hline \multicolumn{3}{|l|}{ Mobilidade Pendular } \\
\hline "In-movente" & & Residia em outro município e trabalha ou \\
\hline \multicolumn{3}{|l|}{ estuda no município A } \\
\hline "Ex-movente" & & Trabalha ou estuda no município A, mas \\
\hline residia em outro município & & \\
\hline
\end{tabular}

Fonte: IBGE. Censo Demográfico 2000.

(1) Esta variável pode ser construída considerando, em separado, a migração interestadual e intra-estadual.

(2) Para os naturais do município A.

TABELA 1

Número de Imigrantes, Emigrantes e Saldo Migratório, segundo Municípios Selecionados

Rondônia - 2000

\begin{tabular}{|c|c|c|c|c|}
\hline Código do & Município & \multirow{2}{*}{ Imigrantes } & \multirow{2}{*}{ Emigrantes } & \multirow{2}{*}{$\begin{array}{c}\text { Saldo } \\
\text { Migratório }\end{array}$} \\
\hline Município & Selecionado & & & \\
\hline 1100015 & Alta Floresta d'Oeste & 3.453 & 2.540 & 913 \\
\hline 1100023 & Ariquemes & 10.100 & 12.055 & -1.955 \\
\hline 1100031 & Cabixi & 917 & 1.485 & -568 \\
\hline 1100049 & Cacoal & 8.875 & 14.383 & -5.508 \\
\hline 1100056 & Cerejeiras & 2.425 & 5.555 & -3.130 \\
\hline 1100064 & Colorado do Oeste & 1.551 & 7.424 & -5.873 \\
\hline 1100072 & Corumbiara & 1.292 & 2.163 & -871 \\
\hline 1100080 & Costa Marques & 1.605 & 1.682 & -77 \\
\hline 1100098 & Espigão d'Oeste & 2.510 & 4.120 & -1.610 \\
\hline 1100106 & Guajará-Mirim & 2.742 & 4.052 & -1.310 \\
\hline
\end{tabular}

Fonte: IBGE. Censo Demográfico 2000.

Nota: Data fixa (1995/2000). 
- migração urbana/rural no município de residência. Imigrante urbano/rural - pessoa que: a) para 1991, em 1o de setembro de 1986 residia na região urbana do município e que em 1 o de setembro de 1991 estava na região rural do mesmo município; b) para 2000, em 31 de julho de 1995 residia na região urbana do município e que em $1^{10}$ de agosto de 2000 estava na região rural do mesmo município;

- saldo migratório rural/urbano no município de residência: diferença entre o item 1 e 2 para 1991 e 2000;

- imigrante intermunicipal do qüinquiênio para um determinado município. Pessoa que: a) para 1991, em 1o de setembro de 1991 foi recenseada na cidade, mas que declarou residir em outro município em $1^{\circ}$ de setembro de 1986; b) para 2000, em 1으 de agosto de 2000 foi recenseada na cidade, mas que declarou residir em outro município em 31 de julho de 1995;

- emigrante intermunicipal do qüinqüênio de um determinado município. Pessoa que: a) para 1991, em 1ํ de setembro de 1986 residia na cidade e em 1ํㅡㄹ de setembro de 1991 foi recenseada em outro município; b) para 2000,

TABELA 2

Emigrantes do Município de Vale do Anari (RO), por Município e Unidade da Federação de Destino Rondônia - 2000

\begin{tabular}{lllr}
\hline $\begin{array}{l}\text { Código do } \\
\text { Município }\end{array}$ & Município de Destino & UF & Migrantes \\
\hline 1100114 & Jaru & RO & 71 \\
1100122 & Ji-Paraná & RO & 28 \\
1100130 & Machadinho d'Oeste & RO & 102 \\
1100155 & Ouro Preto do Oeste & RO & 83 \\
1100346 & Alvorada d'Oeste & RO & 8 \\
1100403 & Alto Paraíso & RO & 7 \\
1100452 & Buritis & RO & 49 \\
1100601 & Cacaulândia & RO & 6 \\
1100700 & Campo Novo de Rondônia & RO & 23 \\
1100940 & Cujubim & RO & 15 \\
1101005 & Governador Jorge Teixeira & RO & 13 \\
1101302 & Mirante da Serra & RO & 6 \\
1101401 & Monte Negro & RO & 5 \\
1101609 & Theobroma & RO & 104 \\
3201308 & Cariacica & ES & 12 \\
4108304 & Foz do Iguaçu & PR & 11 \\
\hline
\end{tabular}

Fonte: IBGE. Censo Demográfico 2000. Nota: Data fixa (1995/2000). em 31 de julho de 1995 residia na cidade e em 1o de agosto de 2000 foi recenseada em outro município;

- saldo migratório ou trocas líquidas migratórias do qüinqüênio do município: para um dado município, será a diferença entre os imigrantes e emigrantes do qüinqüênio considerado, excluindo-se os imigrantes internacionais, ou seja, os moradores no município em 1ำ de setembro de 1991, para 1991, e 1o de agosto de 2000, para 2000, que indicaram residir no exterior em 1을 de setembro de $1986 \mathrm{e}$ 31 de julho de 1995, respectivamente.

Ainda com a informação de "data fixa", é possível estimar a migração intermunicipal segundo a situação do domicílio de destino (se rural ou urbano), e, da mesma forma, no caso dos emigrantes, pode-se definir a situação domiciliar de origem. Conjugando a informação sobre o local de nascimento (naturalidade) com o dado de "data fixa", podese obter para os imigrantes a informação sobre a migração de retorno dos naturais do município. Outro aspecto a considerar seria a divisão dos imigrantes e emigrantes segundo a UF de origem e destino. Assim, é possível definir o montante dos movimentos migratórios dentro da UF (migração intraestadual) e com outras Unidades (migração interestadual).

No aspecto relativo à mobilidade pendular, aplicável exclusivamente para os dados de 2000, as variáveis sugeridas são:

- "in-movente" pendular para uma cidade: pessoa que trabalha ou estuda na cidade e reside em outro município;

TABELA 3

Ex-Movente do Município de Alta Floresta (RO), por Município e Unidade da Federação de Destino Rondônia - 2000

\begin{tabular}{lllc}
\hline $\begin{array}{l}\text { Código do } \\
\text { Município }\end{array}$ & Município onde & UF & Ex-Movente \\
\hline 1100049 & Crabalha ou Estuda & RO & 32 \\
1100122 & Ji-Paraná & RO & 27 \\
1100189 & Pimenta Bueno & RO & 9 \\
1100288 & Rolim de Moura & RO & 28 \\
1100379 & Alto Alegre do Parecis & RO & 21 \\
1101484 & São Felipe d'Oeste & RO & 12 \\
2904902 & Cachoeira & BA & 16 \\
3170107 & Uberaba & MG & 9 \\
4301602 & Bagé & RS & 8 \\
5103403 & Cuiabá & MT & 11 \\
\hline
\end{tabular}

Fonte: IBGE. Censo Demográfico 2000. Nota: Data fixa (1995/2000). 
- "ex-movente" pendular de uma cidade: pessoa que reside na cidade e trabalha ou estuda em outro município;

- saldo pendular de uma cidade:11 diferença entre 1 e 2 .

\section{Indicadores sobre Migração}

Além das variáveis apontadas, alguns indicadores poderão ser calculados para expressar a importância do processo migratório nos municípios. Para o cálculo de indicadores relacionados a qualquer variável demográfica, deve-se ter em conta, com muita clareza, a definição do denominador e do numerador da taxa ou quociente que se está buscando.
Com as informações selecionadas, pode-se construir um quadro de indicadores, tanto em 1991 e em 2000, para cada um dos municípios brasileiros. O primeiro indicador a ser considerado seria a Taxa Líquida Migratória TLM, calculada da seguinte forma: tendo no numerador o resultado da diferença entre o número de imigrantes e emigrantes de determinado município e, no denominador, a população com cinco anos ou mais na data de referência (1991 e 2000).

Considerando para cada município os imigrantes e emigrantes, pode-se calcular a "taxa de imigração" e a "taxa de emigração". O numerador, no caso dos imigrantes, seria o montante daqueles que, não residindo no mu-

\section{MAPA 1}

Distribuição dos Municípios, segundo Volume do Saldo Migratório 1995-2000

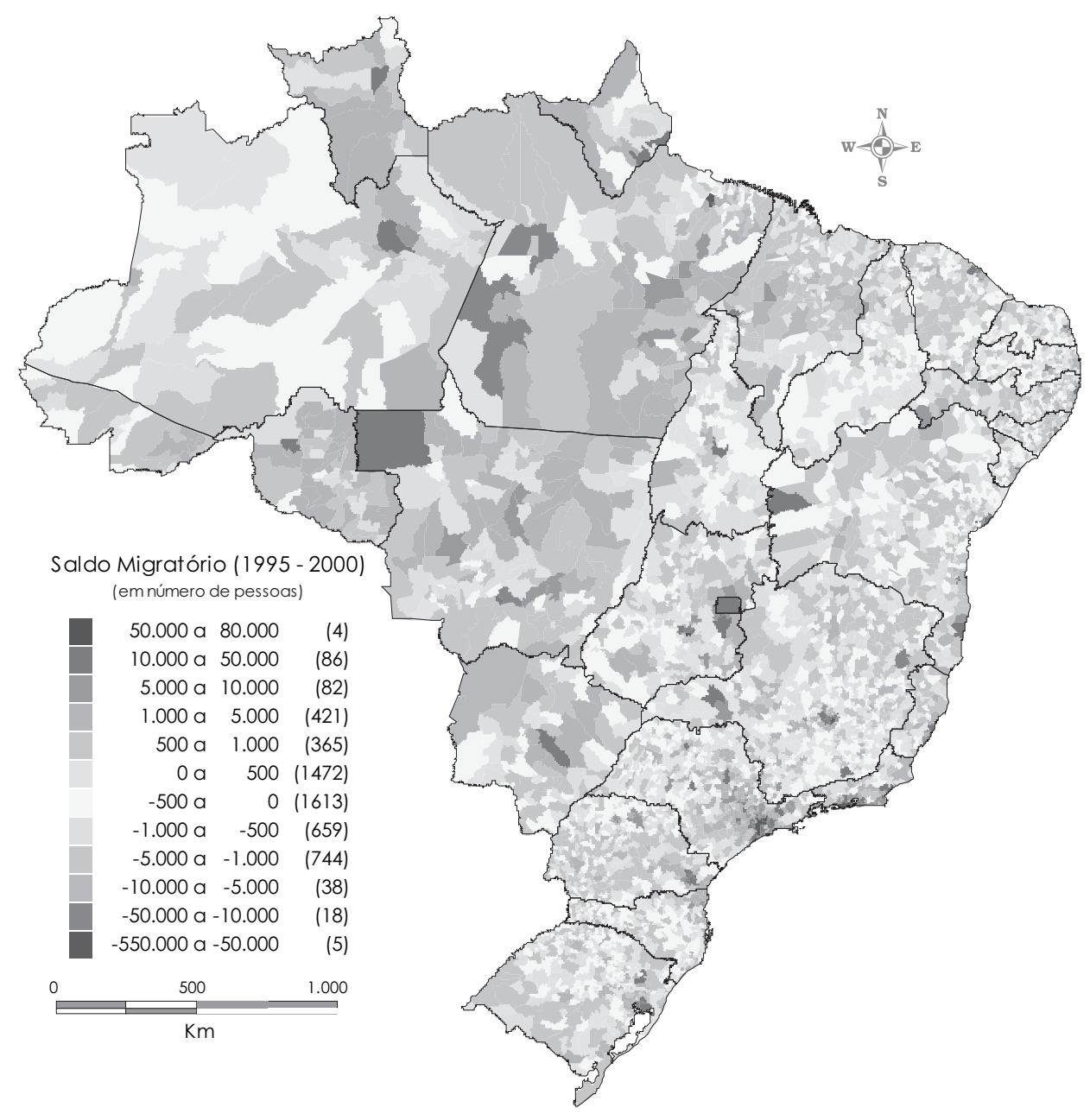

Fonte: IBGE. Censo Demográfico Amostra (2000) - Microdados. 
nicípio no início, entraram no município entre as duas datas consideradas e lá permaneceram. No caso dos emigrantes, aqueles que lá residiam no início, saíram do município, não morreram e residiam em outro município no final do período. O denominador será a população com cinco anos ou mais nos Censos de 1991 e 2000. Apesar de não ser uma taxa no sentido estrito, esse indicador permite avaliar a importância da imigração e emigração, tendo em conta o efetivo populacional. Um proxy do poder de atração ou expulsão do município.

\section{NOTAS}

Trabalho apresentado no XIV Encontro Nacional de Estudos Populacionais, Abep, realizado em Caxambu - MG - Brasil, de 20-24 de setembro de 2004.

1. Condições de Moradia; Desenvolvimento e erradicação da pobreza; Gestão Ambiental; Desenvolvimento Econômico; Governança; e Cooperação internacional.

2. O SNIU pode ser acessado na página do Ministério das Cidades, na Internet (www.cidades.gov.br).

3. No Censo de 1991, perguntou-se o nome do município, situação de domicílio e a UF de residência em $1^{\circ}$ de setembro de 1986.

4. A Pesquisa Mensal de Emprego - PME, pesquisa mensalmente 37.212 domicílios nas regiões metropolitanas de Recife, Salvador, Belo Horizonte, Rio de Janeiro, São Paulo e Porto Alegre. A Pesquisa de Emprego e Desemprego - PED, pesquisa mensalmente 15.720 domicílios nas regiões metropolitanas de São Paulo, Porto Alegre, Recife, Salvador, Belo Horizonte e Distrito Federal.

5. Em 1970, o Brasil contava com 3.951 municípios; 3.991 em 1980; $4.491 \mathrm{em} 1991$ e 5.507 em 2000, quando da realização do censo. Em 1/1/2001 foram agregados à malha municipal mais 54 municípios.

6. Não há informação sobre a emigração das Regiões Metropolitanas - RM, sequer interestaduais. Apenas dos imigrantes da RM cuja UF de residência anterior ou a de cinco anos atrás tenha sido outra.

7. Na realidade, não se trata de um "saldo migratório" no sentido estrito do termo, pois, como os emigrantes internacionais não são contabilizados no censo brasileiro, o mais correto seria defini-lo como "trocas líquidas migratórias", descontados os imigrantes internacionais.

8. Apesar do termo amplamente utilizado ser "migração pendular", a definição mais usual da migração pressupõe a mudança de domicílio permanente. Alguns autores como Cunha (2002) preferem qualificar esse movimento de "mobilidade pendular".

9. Um exemplo do uso de variáveis é apresentado nas Tabelas 1,2 e 3 e no Mapa 1.
10. Em todos os itens são consideradas as pessoas com cinco anos ou mais.

11. Esse "saldo" poderia também ser considerado como fator de atração e avaliado em relação à população do município, controlado pela idade.

\section{REFERÊNCIAS BIBLIOGRÁFICAS}

CARVALHO, J.A.M. de; RIGOTTI, J.I.R. Os dados censitários brasileiros sobre migrações internas: algumas sugestões para análise. Revista Brasileira de Estudos de População, São Paulo, v. 15, n. 2, p. 7-16, 1998.

CARVALHO, J.A.M. de. Migrações internas: mensuração direta e indireta. Revista Brasileira de Estatística, Rio de Janeiro, v. 43, n. 171, p. 549-583, jul./set. 1982.

CUNHA, J.M.P. O uso das PNADs na análise do fenômeno migratório: possibilidades, lacunas e desafios metodológicos. Rio de Janeiro, IPEA, 2002. 87 p. (Texto para Discussão, n. 875).

HAKKERT, R. Fontes de dados demográficos. Abep, 1996. 63 p.

MAGALHÃES M.V. O Paraná e suas regiões nas décadas recentes: as migrações que também migram. Tese (Doutorado) CEDEPLAR/UFMG, Belo Horizonte, 2003.

MARTINE, G. Os dados censitários sobre migrações internas: evolução e utilização. In: Seminário Metodológico dos Censos Demográficos - CENSOS, CONSENSOS E CONTRA-CENSOS, 3., 1984, Ouro Preto-MG. Abep, 1984. p. 183-214.

ONU. Métodos de médición de la migración interna: manual IV. Nueva York: 1972. 436 p.

PRESSAT, R. Dicionaire demographique. Paris: Editions PUF, 1976. $236 \mathrm{p}$.

RIGOTTI, J.I.R. Técnicas de mensuração das migrações a partir de dados censitários: aplicação aos casos de Minas Gerais e São Paulo. Tese (Doutorado) - CEDEPLAR/UFMG, Belo Horizonte, 1999.

Duval Fernandes: Doutor em Demografia e Professor do Programa de Pós-graduação em Geografia e Tratamento da Informação Espacial PUC-Minas (duval@pucminas.br).

Idamila Renata Pires Vasconcellos: Mestre em Geografia e Tratamento da Informação Espacial - PUC-Minas (idamila@pucminas.br).

Artigo recebido em 28 de março de 2005.

Aprovado em 17 de abril de 2005. 